\title{
Role of preoperative CA-125 levels in predicting the DFS and OS in epithelial ovarian cancer
}

\author{
Shashidhar V. Karpurmath, Velukuru Sai Vivek*, Manjunath I. Nandennavar, \\ Veerandra Angadi, Annalakshmi Sekar
}

\begin{abstract}
Department of Medical Oncology, Vydehi Institute of Medical Sciences and Research Center, Bangalore, Karnataka,
\end{abstract} India

Received: 13 September 2017

Accepted: 20 November 2017

*Correspondence:

Dr. Velukuru Sai Vivek,

E-mail: vivsai@gmail.com

Copyright: ( ) the author(s), publisher and licensee Medip Academy. This is an open-access article distributed under the terms of the Creative Commons Attribution Non-Commercial License, which permits unrestricted non-commercial use, distribution, and reproduction in any medium, provided the original work is properly cited.

\begin{abstract}
Background: Ovarian cancer has the highest mortality rate among all the other gynaecologic malignancies. Stage I cancer treated with surgery and adjuvant chemotherapy report a 5-year overall survival of $95 \%$ while this value significantly drops to $25 \%$ in stage IIIC and IV patients. Unfortunately, effective screening methods to detect the early cancer are yet to be identified.

Methods: All the patients diagnosed to have epithelial ovarian carcinoma from January 2012 to December 2014 at our center with pre-treatment CA-125 levels were included in this retrospective study. Disease free survival and overall survival were tabulated either by telephonic conversation or on a regular follow up visit to the hospital.

Results: Among the 69 patients enrolled 38\% of the patients were in the age group of 50-60 years. 58\% of patients had stage 3 disease up front. mean CA-125 levels were lowest in patients with stage I disease and the highest in stage IV disease with a statistically significant rise in CA-125 levels with the stage of disease. Only 52\% of the patients completed the treatment as per protocol. There was a significant negative co relation between the CA-125 levels and survival rates in both the sub groups of patients who received complete and incomplete treatment respectively.

Conclusions: In the present study we would like to conclude that pre-operative CA-125, which has already been included in the screening algorithms like ROCA, has a greater potential to become a prognostic marker. Present study is limited by the small number of patient's and thus larger multi centric studies with better randomization could establish the role of CA-125 as a prognostication marker.
\end{abstract}

Keywords: CA 125, CA ovary, Survival rates

\section{INTRODUCTION}

Carcinoma ovary is the second most common gynaecological cancer. The Incidence of ovarian cancer worldwide is 9.4 per 100000 population in developed countries and an incidence of 5 per 100000 population in developing countries. ${ }^{1}$ Ovarian cancer has the highest mortality rate among all the other gynaecologic malignancies. Stage I cancer treated with surgery and adjuvant chemotherapy report a 5-year overall survival of $95 \%$ while this value significantly drops to $25 \%$ in Stage
IIIC and IV patients. $^{2}$ Unfortunately effective screening methods to detect the early cancer are yet to be identified.

The most important marker for the diagnosis and management of ovarian cancer is the Cancer Antigen 125 (CA-125) discovered initially by Bast and colleagues in 1983. The gene for CA-125 was cloned in 2001 and is called MUC $16 .^{3}$ It is a large trans membrane glycoprotein derived from both coelomic (pericardial, pleura, peritoneum) and Mullerian (fallopian, tubal, endometrial, endocervical) epithelia. ${ }^{4}$ OC 125 and M11 
monoclonal antibodies bind to the CA 125 antigen and are used in its assay's. CA 125 cut off 's using the only the OC 125 monoclonal antibody is less than or equal to $35 \mathrm{U} / \mathrm{ml}$ and using both the antibodies is less than or equal to $20 \mathrm{U} / \mathrm{ml}$. The serum levels of CA 125 are influenced by coffee consumption, smoking, age at menarche, age at menopause or associated hormonal therapies. High serum values up to $100 \mathrm{U} / \mathrm{ml}$ can be encountered in physiological conditions like menopause, pregnancy and other conditions like endometriosis (lower than $100 \mathrm{U} / \mathrm{ml}$ in $88 \%$ of the cases), hepatic diseases (40$48 \%$ of cases), uterine fibromas, acute pancreatitis $(38 \%$ of cases), pericarditis or cardiac failure..$^{5}$

Malignant Ovarian tumors especially of the epithelial origin are associated with high levels of CA-125. Apart from ovarian carcinomas, endometrial cancer, cervical cancer, breast tumors, gastro-intestinal tumors, lymphomas, colorectal tumors, hepatic, pancreatic and biliary tree tumors are associated with high levels of CA$125 .^{6,7}$

Multiple studies have been conducted with to see the prognostic use of CA-125 in ovarian carcinomas. It has been concluded with sufficient evidence that postoperative CA-125 level is an independent prognostic factor in patients with invasive ovarian cancer. ${ }^{8}$

In a study done by Malkasian GD Jr et al it was found that if only non-mucinous epithelial ovarian carcinomas were considered, CA 125 levels greater than $65 \mathrm{U} / \mathrm{ml}$ predicted malignancy with a sensitivity of $91 \%$ for all patients. Greater sensitivity and specificity were observed in the postmenopausal subgroup than in the premenopausal subgroup. In the postmenopausal group with a $63 \%$ prevalence of ovarian cancer the predictive positive value was $98 \%$ and the negative predictive value was $72 \%$. In a premenopausal population with a $15 \%$ prevalence of ovarian cancer the predictive value for a positive test was $49 \%$, while the predictive value for a negative test was $93 \% .^{9}$

In regard to the pre-operative or pre-treatment CA-125 levels and survival rates in ovarian cancer, studies done by Cooper BC et al, Geisler JP et al, Nagele F et al and Moebus $\mathrm{V}$ et al show that CA-125 levels can predict the survival rates in epithelial ovarian cancer. ${ }^{10-13}$

In the present study conducted at a tertiary care hospital in Bangalore, India we wanted to compare the preoperative CA-125 levels and the disease-free survival and overall survival in patients who were diagnosed to have Invasive carcinoma ovary.

\section{METHODS}

All the patients diagnosed to have epithelial ovarian carcinoma from January 2012 to December 2014 at our center with pre-treatment CA-125 levels were included in this retrospective study. The standard treatment was considered to be surgery followed by 6 cycles of Paclitaxel and Carboplatin or 3 cycles of neo-adjuvant chemotherapy with the same agents followed by surgery and adjuvant chemotherapy for early and advanced FIGO stages.

Disease free survival and overall survival were tabulated either by telephonic conversation or on a regular follow up visit to the hospital.

\section{Statistical analysis}

Data was entered into Microsoft excel data sheet and was analyzed using SPSS 22 version software. Categorical data was represented in the form of frequencies and proportions. Chi-square test was used as test of significance for qualitative data. Continuous data was represented as mean and standard deviation. Independent $\mathrm{t}$ test or Mann Whitney $\mathrm{U}$ test was used as test of significance to identify the mean difference between two quantitative variables and qualitative variables respectively.

Graphical representation of data: MS Excel and MS word were used to obtain various types of graphs such as bar diagram, Pie diagram and Scatter plots. Pearson correlation or Spearman's correlation was done to find the correlation between two quantitative variables and qualitative variables respectively.

Overall survival and disease-free survival of the subjects was analyzed by Kaplan Meier Survival analysis and Cox regression model. Kaplan Meier survival curve was used to depict the same.

$\mathrm{p}$ value (probability that the result is true) of $<0.05$ was considered as statistically significant after assuming all the rules of statistical tests.

\section{Statistical software:}

MS Excel, SPSS version 22 (IBM SPSS Statistics, Somers NY, USA) was used to analyze data. EPI Info (CDC Atlanta), Open Epi, Med calc and Medley's desktop were used to estimate sample size, odds ratio and reference management in the study.

\section{RESULTS}

Among the 69 patients enrolled in the study majority of the patients were in the age group of 51-60 years (34.8\%). $23 \%$ of the patients were in age groups of $41-50$ years and more than 60 years respectively. $19 \%$ of the patients were in the age group of less than 40 years (Figure 1).

$58 \%$ of the patients had FIGO stage III disease. $21 \%$ of the patients were had stage 4 cancer, $15 \%$ of the patients had stage 1 and only $4.30 \%$ of the patients had stage 2 cancer (Figure 2). 


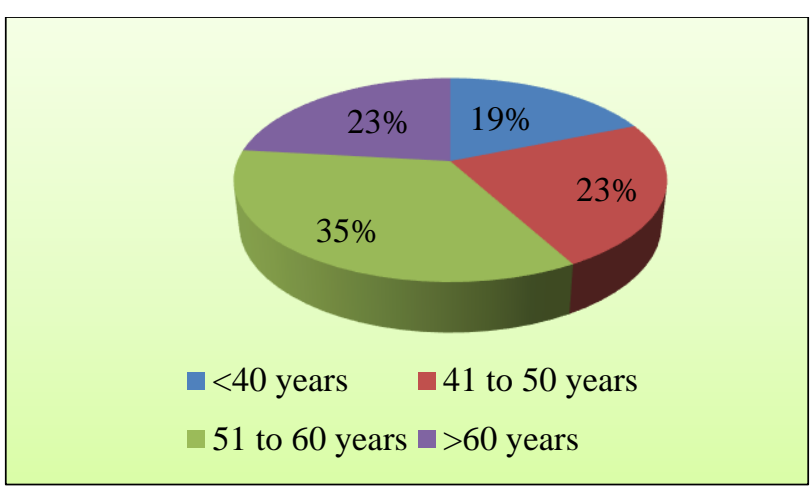

Figure 1: Age distribution of the patients.

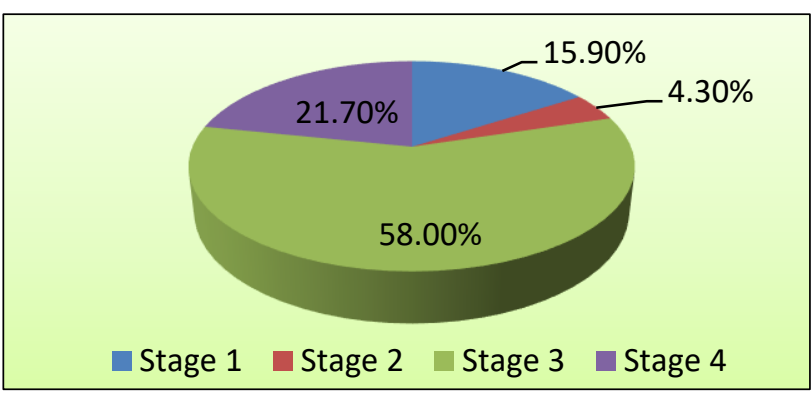

Figure 2: Stage of cancer at diagnosis among the patients.
The Mean CA-125 levels were lowest in stage I disease and highest in Stage IV disease (Table1, Figure 3), the rise in CA-125 levels with the stage of the disease was statistically significant, $\mathrm{P}$ value $<0.001$.

The mean CA-125 level in patients with stage 1 was 99 $\mathrm{U} / \mathrm{ml}$, stage 2 was $1391.3 \mathrm{U} / \mathrm{ml}$, stage 3 was $1704.9 \mathrm{U} / \mathrm{ml}$ and stage 4 was $1990.7 \mathrm{IU} / \mathrm{ml}$.

Table 1: Mean CA-125 levels of the patients according the stage at diagnosis.

\begin{tabular}{|c|c|c|c|}
\hline \multicolumn{4}{|c|}{ CA-125 } \\
\hline & & Mean & SD \\
\hline \multirow{4}{*}{ Stage } & Stage 1 & 99.3 & 128.6 \\
\hline & Stage 2 & 1391.3 & 824.3 \\
\hline & Stage 3 & 1704.9 & 2481.6 \\
\hline & Stage 4 & 1990.7 & 1676.7 \\
\hline $\mathrm{P}$ valu & & $<0.001$ & \\
\hline
\end{tabular}

7 patients (77.8\%) with stage 1 cancer had DFS more than 2 years and 8 patients $(72.7 \%)$ with stage 1 had an OS more than 2 year. 9 patients $(47.4 \%)$ had a DFS of more than 2 years while 16 patients $(41 \%)$ had an OS more than 2 year. None of the patients in stage 4 had DFS or OS more than 2 years (Table 2).

Table 2: 2-year OS and DFS of the study group with respect to stage.

\begin{tabular}{|c|c|c|c|c|c|c|c|c|c|c|}
\hline & & \multicolumn{8}{|l|}{ Stage } & \multirow{3}{*}{ P value } \\
\hline & & \multicolumn{2}{|l|}{ Stage 1} & \multicolumn{2}{|l|}{ Stage 2} & \multicolumn{2}{|c|}{ Stage 3} & \multicolumn{2}{|l|}{ Stage 4} & \\
\hline & & Count & $\%$ & Count & $\%$ & Count & $\%$ & Count & $\%$ & \\
\hline \multirow[t]{2}{*}{$\begin{array}{l}\text { Overall } \\
\text { survival }\end{array}$} & $<24$ months & 3 & $27.3 \%$ & 3 & $100.0 \%$ & 23 & $59.0 \%$ & 14 & $100.0 \%$ & \multirow[t]{2}{*}{$0.001 *$} \\
\hline & $>24$ months & 8 & $72.7 \%$ & 0 & $0.0 \%$ & 16 & $41.0 \%$ & 0 & $0.0 \%$ & \\
\hline \multirow[t]{2}{*}{ DFS } & $<24$ months & 2 & $22.2 \%$ & 1 & $100.0 \%$ & 10 & $52.6 \%$ & 2 & $100.0 \%$ & \multirow{2}{*}{122} \\
\hline & $>24$ months & 7 & $77.8 \%$ & 0 & $0.0 \%$ & 9 & $47.4 \%$ & 0 & $0.0 \%$ & \\
\hline
\end{tabular}

Table 3: Correlation between CA -125 and DFS and overall survival among subjects who received complete treatment.

\begin{tabular}{|lllll} 
& & CA-125 & DFS & OS \\
Pearson & 1 & -0.386 & $-0.377^{*}$ \\
CA-125 & \begin{tabular}{l} 
correlation \\
\cline { 2 - 4 }
\end{tabular} & 1 & 0.084 & $0.023^{*}$ \\
\cline { 2 - 5 } & P value & & 21 & 36
\end{tabular}

36 patients completed the treatment as per the guidelines (52\%), 23 patients received incomplete treatment (33\%) and 10 patients $(15 \%)$ did not receive any treatment.

In this study statistically, significant negative correlation was seen with respect to overall survival in patients who received complete treatment (Table 3 and Figure 3). The DFS was not statistically significant.

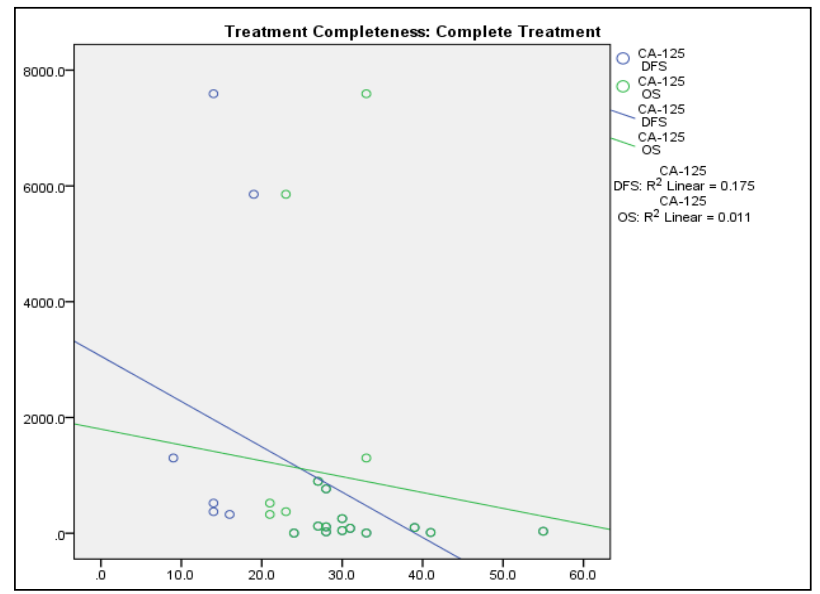

Figure 3: Scatter plot showing correlation between CA-125 and overall survival among those who received complete treatment. 
In this study statistically, significant negative correlation was seen with respect to overall survival in patients who received incomplete treatment (Table 4 and figure4). The DFS was not statistically significant.

Table 4: Correlation between CA-125 and DFS and overall survival among subjects who received incomplete treatment.

\begin{tabular}{|lllll} 
& & CA-125 & DFS & OS \\
CA-125 & $\begin{array}{l}\text { Pearson } \\
\text { correlation }\end{array}$ & 1 & -0.588 & $-0.424^{*}$ \\
\cline { 2 - 5 } & P value & & 0.074 & $0.018^{*}$ \\
\cline { 2 - 5 } & $\mathrm{N}$ & 31 & 10 & 31
\end{tabular}

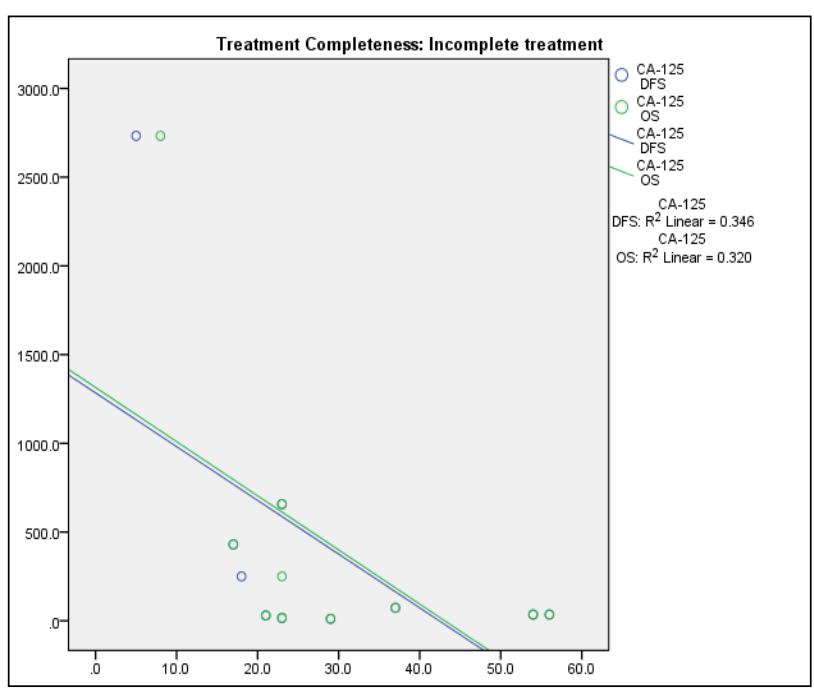

Figure 4: Scatter plot showing correlation between CA -125 and overall survival among those who received incomplete treatment.

Table 5: Area under the curve.

\section{Test Result Variable(s): CA-125}

\begin{tabular}{lllll}
\multirow{2}{*}{ Area } & \multirow{2}{*}{ SE } & P value & \multicolumn{2}{l}{$\begin{array}{l}\text { Asymptotic } 95 \% \\
\text { confidence interval }\end{array}$} \\
\cline { 5 - 6 } & & & $\begin{array}{l}\text { Lower } \\
\text { bound }\end{array}$ & $\begin{array}{l}\text { Upper } \\
\text { bound }\end{array}$ \\
\hline 0.800 & 0.058 & $<0.001^{*}$ & 0.687 & 0.913 \\
\hline
\end{tabular}

Table 6: Coordinates of the curve.

\begin{tabular}{|lll|}
\hline $\begin{array}{l}\text { Positive if greater } \\
\text { than or equal to }\end{array}$ & Sensitivity & Specificity \\
\hline 2.4 & $100 \%$ & $0 \%$ \\
\hline 14.5 & $100 \%$ & $14.3 \%$ \\
\hline 133.5 & $95.1 \%$ & $60.7 \%$ \\
\hline 258.5 & $82.9 \%$ & $67.9 \%$ \\
\hline 403 & $70.7 \%$ & $71.4 \%$ \\
\hline 508 & $65.9 \%$ & $75 \%$ \\
\hline 9112 & $0 \%$ & $100 \%$ \\
\hline
\end{tabular}

CA-125 had area under the curve of 0.8 in detecting the outcome among subjects. Hence has a high ability of predicting outcome. CA-125 at $258.5 \mathrm{U}$ had highest sensitivity and specificity (Table 5, Table 6 and Figure $5)$.

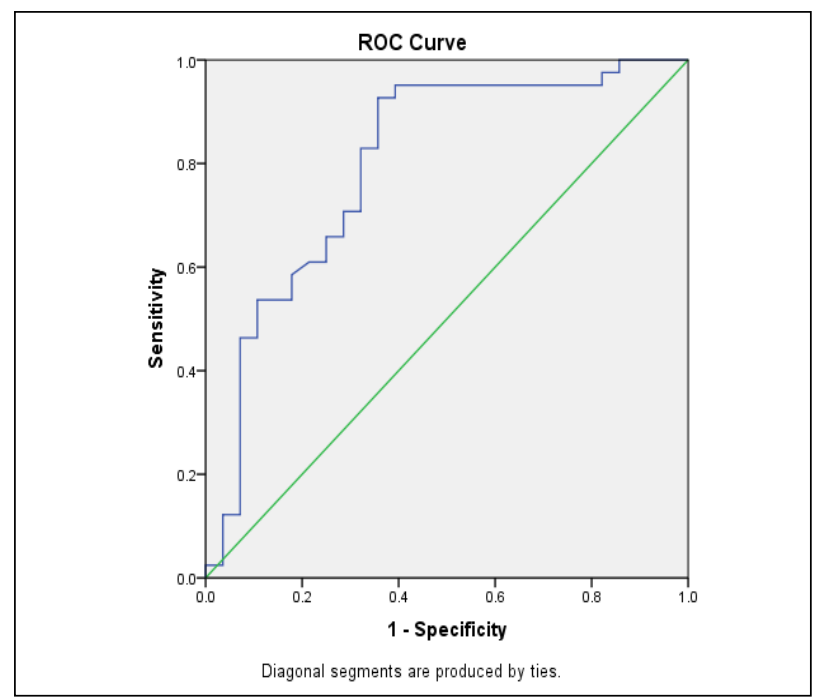

Figure 5: ROC Curve representing the sensitivity and specificity of CA-125.

\section{DISCUSSION}

Epithelial ovarian cancer is known to be most common cause of death among the gynecological malignancies and $5^{\text {th }}$ most common cause of death among all cancers. A number of biomarkers have been developed to monitor responses to chemotherapy, relapse and disease progression in carcinoma ovary and among them CA-125 has been the most extensively studied. The use of CA 125 at the time of diagnosis for prediction of survival rates is inconclusive though has been studied in multiple studies.

The age at diagnosis in this study in majority of the patients was in the age group of was 51-60 years (34.8\%), this is almost a decade earlier to the mean age of diagnosis in the western population as per the SEER database but coincides age at diagnosis in Indian population as per the studies done by Surendra KS et al and Basu P et al. ${ }^{14} 58 \%$ of the patients had FIGO stage III disease which is the most common stage at diagnosis in the western population and Indian population.

The mean CA-125 levels were higher in the patients with stage IV disease compared to stage I disease, a trend that correlates with the trial done by Morales-Vasquez $\mathrm{F}$ et al on 1009 patients with carcinoma ovary. The 2-year OS and DFS of the patients was inversely proportional to the stage of the disease at diagnosis concurring with the epidemiological data for carcinoma ovary at the SEER data base. Only $52 \%$ of the patients completed the full treatment, which indicates that compliance of the patients is poor, and communication and counseling of the patient and relatives will definitely increase the adherence to treatment. CA 125 levels in the patients had a negative correlation with the survival rates in concurring with the 
observations made by Brain $\mathrm{C}$ cooper et al, Nagele $\mathrm{F}$ et al who undertook similar retrospective analysis to compare the two parameters. In addition to this we compared CA 125 with 2-year OS and DFS in patients who completed treatment and in those who did not. ${ }^{10,12}$ The negative correlation observed was seen in both the groups thus indicating that pretreatment CA-125 level is an independent prognostic marker for survival in carcinoma ovary.

Present study is limited by the small number of patient's and thus larger multi centric studies with better randomization could establish the role of CA-125 as a prognostication marker

\section{CONCLUSION}

In this study we would like to conclude that pre-operative CA 125, which has already been included in the screening algorithms like ROCA, has a greater potential to become a prognostic marker.

Funding: No funding sources

Conflict of interest: None declared

Ethical approval: The study was approved by the Institutional Ethics Committee

\section{REFERENCES}

1. Siegel R, Naishadham D, Jemal A. Cancer statistics, 2013. CA: A Cancer J Clinicians. 2013;63(1):11-30.

2. Hoskins WJ. Prospective on ovarian cancer: why prevent?. J Cellular Biochem. 1995;59(S23):189-99.

3. Bast Jr RC, Klug TL, John ES, Jenison E, Niloff JM, Lazarus $\mathrm{H}$, et al. A radioimmunoassay using a monoclonal antibody to monitor the course of epithelial ovarian cancer. New England J Med. 1983;309(15):883-7.

4. Ma Y, Zhang P, Wang F, Yang J, Yang Z, Qin H. The relationship between early embryo development and tumourigenesis. J Cellular Molecular Med. 2010;14(12):2697-701.

5. Gadducci A, Cosio S, Zola P, Landoni F, Maggino T, Sartori E. Surveillance procedures for patients treated for epithelial ovarian cancer: a review of the literature. Int J Gynecol Cancer. 2007;17(1):21-31.

6. Topalak O, Saygili U, Soyturk M, Karaca N, Batur Y, Uslu T, et al. Serum, pleural effusion, and ascites
CA-125 levels in ovarian cancer and nonovarian benign and malignant diseases: a comparative study. Gynecol Oncol. 2002;85(1):108-13.

7. Malaguarnera G, Giordano M, Paladina I, Rando A, Uccello M, Basile F, et al. Markers of bile duct tumors. World J Gastrointestinal Oncol. 2011;3(4):49.

8. Gupta D, Lis CG. Role of CA125 in predicting ovarian cancer survival-a review of the epidemiological literature. J Ovarian Res. 2009;2(1):13

9. Malkasian GD, Knapp RC, Lavin PT, Zurawski VR, Podratz KC, Stanhope CR, et al. Preoperative evaluation of serum CA 125 levels in premenopausal and postmenopausal patients with pelvic masses. Discrimination of benign from malignant disease. American J Obstet Gynecol. 1988;159(2):341-6.

10. Cooper BC, Sood AK, Davis CS, Ritchie JM, Sorosky JI, Anderson B, et al. Preoperative CA 125 levels: an independent prognostic factor for epithelial ovarian cancer. Obstet Gynecol. 2002;100(1):59-64.

11. Geisler JP, Miller GA, Lee TH, Harwood RM, Wiemann MC, Geisler HE. Relationship of preoperative serum CA-125 to survival in epithelial ovarian carcinoma. J Reprod Med. 1996;41(3):140-2.

12. Nagele F, Petru E, Medl M, Kainz C, Graf AH, Sevelda P. Preoperative CA 125: an independent prognostic factor in patients with stage I epithelial ovarian cancer. Obstet Gynecol. 1995;86(2):259-64.

13. Möbus V, Kreienberg R, Crombach G, Würz H, Caffier H, Kaesemann H, et al. Evaluation of CA 125 as a prognostic and predictive factor in ovarian cancer. J Tumor Marker Oncol. 1988;3(2):251-8.

14. Basu P, De P, Mandal S, Ray K, Biswas J. Study of 'patterns of care of ovarian cancer patients in a specialized cancer institute in Kolkata, eastern India. Indian J Cancer. 2009;46(1):28.

15. Morales-Vásquez F, Pedernera E, Reynaga-Obregón J, López-Basave HN, Gómora MJ, Carlón E, et al. High levels of pretreatment CA125 are associated to improved survival in high grade serous ovarian carcinoma. J Ovarian Res. 2016;9(1):41.

Cite this article as: Karpurmath SV, Vivek VS, Nandennavar MI, Angadi V, Sekar A. Role of preoperative CA-125 levels in predicting the DFS and OS in epithelial ovarian cancer. Int J Reprod Contracept Obstet Gynecol 2018;7:69-73. 